\title{
Analysis of factors influencing the overall effect of racecadotril on childhood acute diarrhea. Results from a real-world and post-authorization surveillance study in Venezuela
}

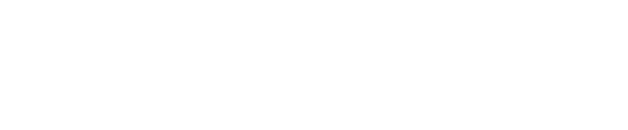

\section{Jose Chacón}

On behalf of the Racecadotril Post-authorization Record Group; Centro Clinico Profesional Caracas, Caracas, Venezuela
Correspondence: Jose Chacón

Centro Clínico Profesional Caracas,

Caracas, Venezuela

Tel +582123602495

Fax +582123638596

Email josechacon24@gmail.com
Abstract: Drug efficacy might differ from clinical trial results when performed in clinical daily conditions. Therefore, it is mandatory to conduct trials about effectiveness to improve external validity. This post-authorization, open-label, noncontrolled, prospective, multicenter, observational, and naturalistic trial was designed to search for factors influencing the racecadotril overall effect on childhood acute watery diarrhea in a real-world setting of Venezuela. There were 3,873 children with acute watery diarrhea treated with racecadotril, an enkephalin breakdown blocker plus oral rehydration therapy by 97 pediatricians. Evaluations were carried out daily until emission of two consecutive formed stools or absence of watery bowel movements for 24 hours. The primary end-point was time-to-relief, defined as the time from first racecadotril dose to the last watery bowel movement time. Age, gender, nursing type, nursing status during diarrhea, diarrhea severity, and co-medication were considered as factors in the statistical analysis. The primary end-point was evaluated by factors using UNIANOVA, and post-hoc tests were done. A multiple regression analysis was carried out to identify factors affecting drug performance, racecadotril effectiveness and tolerability overall assessment was searched by physicians and patients, and inter-observer agreement was evaluated by kappa statistics. The mean time-to-relief was $18.5 \pm 12.5$ hours [ $95 \%$ confidence interval $17.9-19.0$ ] and the diarrhea severity was the only variable with significant and independent weight on racecadotril effectiveness explaining $23 \%$ of time-to-relief variance, but even in severe diarrhea cases this time was less than 24 hours. High agreement about satisfactory perception on effectiveness and tolerability was reached among physicians and patients. In conclusion, the racecadotril overall effect, evaluated in a real-world setting of Venezuela, was in agreement with results of some earlier controlled trials. It was only influenced by severity of diarrhea episode, as well as being considered an effective and well tolerated treatment by physicians and patients.

Keywords: childhood acute diarrhea, naturalistic, racecadotril, real-world

\section{Introduction}

Results of drug efficacy trials are affected by less controlled conditions of clinical daily practice. ${ }^{1}$ Therefore, the performance of a drug might be slightly different from that of more controlled settings, such as an experimental clinical assessment. This is why it is so important to show the performance of a drug in a real-world setting, once its efficacy has already been shown, in order to extend external validity of these results. Nutritional, socioeconomic and cultural factors, as well as co-prescription and co-morbidity might have some influence on drug effect of controlled trials, especially in diarrhea, a pathology influenced by multiple variables related to poverty and impaired sanitary 
conditions, as seen in a Venezuelan ordinary clinical setting. Therefore, it is necessary to show effectiveness, ie, evaluate drug performance beyond controlled clinical trials. ${ }^{1-4}$

Provided that it is necessary to know overall performance of a drug to estimate its therapeutic utility, efficacy data from controlled trials are not enough. It is also relevant to evaluate effectiveness data obtained from routine clinical practice because both are complementary. ${ }^{5}$ Effectiveness studies improve external validity of experimental trials because they are performed on larger noncontrolled samples from real-world patients. ${ }^{6-7}$

Acute childhood diarrhea is a disease influenced by socioeconomic issues which have an impact on evolution and outcomes; in Venezuela, diarrhea is a main cause of mortality in children younger than five years, only exceeded by respiratory diseases. In addition, acute diarrhea has high morbidity figures and also demands a great consumption of economic resources. ${ }^{8}$

Racecadotril, a pro-drug metabolized to thiorphan, its active metabolite, is an enkephalin breakdown blocking agent which inhibits intestinal hypersecretion in acute watery diarrhea and whose efficacy and safety has been proven in European and Latin-American countries in controlled clinical trials. ${ }^{9-13}$ To our knowledge racecadotril performance in a real world setting, having taken into account factors affecting its effectiveness, has not been studied so far. The objective of this study, using a naturalistic approach ${ }^{14}$ and data from Racecadotril Post-authorization Record (RPR), was to provide quantitative data about racecadotril overall effect in acute watery diarrhea and identify potential modifying factors in children coming from a real-world setting.

\section{Patients and methods}

The RPR was an initiative carried out simultaneously in 13 regions of Venezuela from September 2005 (first patient recorded) until April 2006 (last patient recorded). It was aimed at providing a systematic record about clinical and therapeutic topics relating to the use of racecadotril by pediatricians in children with acute watery diarrhea in a noncontrolled setting, and also to get a database to search topics concerning to racecadotril performance in a Venezuelan ordinary clinical practice. This open-label, noncontrolled, prospective, multicenter, observational, and naturalistic study is the first collaboration of RPR Group. Sample collection was completed in two timeframes, the first one lasting from September until December 2005 in which 666 children were recruited and evaluated by 27 physicians and the second one from January to April 2006 in which 3,107 more patients were included by 70 pediatricians. The final sample was 3,873 children, of which 3,679 (94.9\%) were analyzed after excluding those with incomplete data.

\section{Case report form (CRF)}

A group of three pediatricians (MD, LM, and $\mathrm{MG}^{\dagger}$ ), highly trained in acute diarrhea management, assessed the feasibility of recording number, time, and characteristics of bowel movements (BMs) during diarrhea in outpatients by parents at home after careful training by physicians. A first draft of CRF was designed which included a set of clinical and demographic data and was evaluated by them for feasibility and comprehensiveness using a simple questionnaire ad hoc. Disagreements were solved by consensus and a final CRF was completed, after agreement was achieved by evaluators and suggested changes were made.

\section{Data collection}

Ninety seven pediatricians, selected according to predefined criteria, formed the RPR Group and recruited patients in a consecutive fashion; they were supported by a 40-member team which carried out the logistical operations all over the country, such as delivery of study items to physicians. Completed CRFs were sent back via mail to the headquarters based in Guarenas city and data were introduced into a database after excluding CRFs with serious missing data, namely those relating to duration of diarrhea.

\section{Study medication}

The study medication consisted of granulated powder in sachets containing 10 and $30 \mathrm{mg}$ of racecadotril (Hidrasec ${ }^{\circledR}$, Ferrer Grupo, Barcelona, Spain), a pro-drug metabolized to thiorphan, an enkephalin breakdown blocker and intestinal water hypersecretion inhibitor agent in acute watery diarrhea, indicated for children older than three months old at doses of $1.5 \mathrm{mg} / \mathrm{kg} /$ dose ter in die.

\section{Patients}

A total of 3,873 patients aged three months to 12 years old and suffering from acute watery nonspecific diarrhea from 13 regions of Venezuela (Caracas DC, Zulia, Mérida, Táchira, Lara, Aragua, Carabobo, Vargas, Miranda, Monagas, Anzoátegui, Nueva Esparta, and Bolívar), were treated by 97 pediatricians in an outpatient setting. Diarrhea was defined as three or more watery stools 24 hours prior to first racecadotril dose. Because of missing data among variables and restriction of analysis to paired data, assessments of individual parameters might have a different number of patients. 
Because this was a noninterventional surveillance study, no restrictions were enforced regarding inclusion and exclusion criteria of patients and the racecadotril was used by the physicians according to Venezuelan health authority's regulations.

\section{Study parameters}

Patients were included in the RPR according to the judgment of pediatricians belonging to this research group. Evaluations were carried out by physicians at baseline and daily until stopping of watery BMs. Frequency of visits was adjusted according to disease severity and short admission periods were allowed if needed. Date and time of the first watery $\mathrm{BM}$ and total BMs in previous 24 hours were recorded. Age, gender, nursing type, diarrhea severity, nursing status during diarrhea, and co-medication were the clinical and demographic characteristics recorded. The first racecadotril dosing time was also recorded to get the time-to-relief (TTR), as have been used in other trials. ${ }^{15}$ During the trial, BMs were recorded daily for time and consistency by a self-assessment form filled in by the child's parents at home. Finally, all physicians in this trial were encouraged to inform any adverse drug effect (ADE) to Authorities Health, following usual procedures in Venezuela.

\section{Biometric evaluation}

The primary effectiveness endpoint of this analysis was TTR, considered a dependent variable in the statistical analysis and defined as the time between the first racecadotril dose given by physician and the start-point of the first 24 hour period with no watery BMs. The watery stools were defined according to the Bristol Stool Scale. ${ }^{16}$ Patients were included in the database for final analysis if the racecadotril first dosing time had been recorded in CRFs. Patients with missing data concerning to time or stool consistency during the follow-up were not analyzed because it was not possible to get the end-point.

TTR was statistically evaluated by UNIANOVA for patient characteristics: age, gender, nursing type (breastfeeding, bottle feeding, or mixed feeding), nursing status during diarrhea (nursing or no nursing), co-medication, and diarrhea severity which were graded according to the number of watery stools in the 24 hour period prior to inclusion into the study $($ mild $=3-4$, moderate $=5-7$, and severe $\geq 8)$. ${ }^{15,17}$ A post hoc test was used to identify potentially significant intra-group differences. Spearman's rho test was used to examine significant correlations. A multiple regression analysis was used to estimate independent effects of factors on the study end-point. Finally, diarrhea evolution was plotted using Kaplan-Meier technique. ${ }^{18}$

A six-point Likert score, with Excellent as best score and Very poor as the worst one, was used to search physicians' and patients' (or parents') evaluation of treatment effectiveness for overall illness relief and for overall tolerability. The inter-observer agreement of both prior mentioned outcomes was done by quadratic-weighted kappa statistics.

The data were analyzed using the Statistical Package for Social Sciences (SPSS; 12.0 version SPSS Inc, Chicago, IL), and the Epidemiological Analysis from Tabulated Data (EPIDAT, 3.1 version Organización Panamericana de la Salud, Washington D.C.). A $P$ value $<0.05$ was considered significant.

\section{Results}

A total of 3,873 children aged three months to 12 years old with watery acute diarrhea of any etiology coming from 13 regions of Venezuela were treated with racecadotril $(1.5 \mathrm{mg} / \mathrm{kg} /$ dose ter in die) plus standard therapy including oral rehydration therapy (ORT) by 97 pediatricians of the RPR Group. After excluding 194 CRFs because of serious missing data, final sample for analysis was 3,679 patients, mainly younger than seven years old and consistent with acute diarrhea morbidity data in Venezuela. ${ }^{8}$ More than half $(53.7 \%)$ were male and the sample age-weight ratio was over the 10th percentile, according to Venezuelan values (data not shown). ${ }^{19}$ At baseline, $24.3 \%$ of children were breast-fed, the rest had other types of lactation (bottle or mixed feeding). As usual in Venezuela, nursing was stopped during diarrhea in $33 \%$ of the children due to parents' decision, not showing any significant difference by age $\left(\chi^{2}=3.06, P=0.39\right)$. Approximately $83 \%$ of the patients had a moderate-to-severe diarrhea; however, this criterion was used only with comparative purposes and did not intend to reflect the current patient clinical state. The cases of severe diarrhea were mostly children younger than seven years old (93.4\%) and $80.73 \%$ of them were younger than four years. All patients were treated with ORT according to standard guidelines, and the most commonly used co-medication were probiotics (28.9\%) (Table 1).

\section{Racecadotril effect on TTR}

The mean TTR was $18.5 \pm 12.5$ hours $(95 \%$ confidence interval [CI]: 17.9-19.0) and pre-treatment time, ie, the mean time from first watery stool to first racecadotril dose, was $7.9 \pm 7.8$ hours ( $95 \%$ CI: $7.3-8.6$ ), accordingly, the mean overall diarrhea time was $26.7 \pm 23.6$ hours (95\% CI: 25.9-27.6), 
Table I Clinical and demographic data of the study population

\begin{tabular}{|c|c|}
\hline $\begin{array}{l}\text { Pre-treatment time, } * \text { mean } \pm \text { SD } \\
(95 \% \mathrm{Cl}) \text {, hours }\end{array}$ & $7.9 \pm 7.8(7.3-8.6)$ \\
\hline $\begin{array}{l}\text { Time-to-relief, }{ }^{* *} \text { mean } \pm \text { SD } \\
(95 \% \mathrm{Cl}) \text {, hours }\end{array}$ & $18.5 \pm 12.5(17.9-19.1)$ \\
\hline $\begin{array}{l}\text { Diarrhea overall time, } * * * \text { mean } \pm S D \\
(95 \% \mathrm{Cl}) \text {, hours }\end{array}$ & $26.7 \pm 23.6(25.9-27.6)$ \\
\hline \multicolumn{2}{|l|}{ Age groups, ${ }^{20,21} \%$} \\
\hline Younger infants (I-II months of age $)^{\S}$ & 28.2 \\
\hline Older infants (I2-23 months of age) & 28.8 \\
\hline Pre-school children ( $2-6$ years of age) & 35.0 \\
\hline School children (7-12 years of age) & 7.7 \\
\hline \multicolumn{2}{|l|}{ Weight, mean \pm SD $(95 \% \mathrm{Cl})$} \\
\hline Global mean & $13.3 \pm 8.5(13.0-13.7)$ \\
\hline Younger infants & $7.9 \pm 3.2(7.7-8.1)$ \\
\hline Older infants & $10.0 \pm 2.3(9.8-10.2)$ \\
\hline Pre-school children & $16.5 \pm 7.1(16.0-16.9)$ \\
\hline School children & $30.3 \pm 11.8(28.7-31.9)$ \\
\hline \multicolumn{2}{|l|}{ Gender, male \% } \\
\hline Male & 53.7 \\
\hline \multicolumn{2}{|l|}{ Nursing type \% } \\
\hline Breast feeding & 24.3 \\
\hline Bottle feeding & 62.9 \\
\hline Mixed feeding & 12.8 \\
\hline \multicolumn{2}{|l|}{ Nursing status $\%$} \\
\hline Nursing & 66.8 \\
\hline No nursing & 33.2 \\
\hline \multicolumn{2}{|l|}{ Diarrhea severity****\% } \\
\hline Mild & 17.5 \\
\hline Moderate & 41.0 \\
\hline Severe & 41.5 \\
\hline \multicolumn{2}{|l|}{ Co-medication \% } \\
\hline ORT & 100 \\
\hline Probiotics & 4.6 \\
\hline Antibiotics & 2.5 \\
\hline Poypharmacy & 37.3 \\
\hline
\end{tabular}

Notes: *Time from first watery stool to first racecadotril dose; **Time from first racecadotril dose to last watery stool recorded; ***Time from first watery stool to last watery stool recorded; *****Total watery bowel movements 24 hours before treatment; §Only children older than three months of age were included according to product prescrition information.

taking into account our end-point criterion. The rate of recovery over time in the whole sample of children is show in Figure 1, using the Kaplan-Meier technique. The rate of unsolved diarrhea was defined as the persistence of watery stools at any time. The median duration of the primary endpoint overall was 18.48 hours (95\% CI: 17.0-19.0), which means that $50 \%$ of the sample was free of watery stools 18 hours after racecadotril first dose. Moreover, seven out of every 10 children had solved their watery diarrhea within the first 24 hours, $90 \%$ at 36 hours, and only $2 \%$ of the sample had watery diarrhea which lasted $56.6 \pm 9.1$ hours.

We performed a general linear model (UNIANOVA) to search potential associations among patient characteristics and TTR, considered a dependent variable in the model.
A Bonferroni test was used to identify significant intra-group differences. Diarrhea severity and co-medication were the only variables showing statistical significant association with the end-point (Table 2). The longest watery stool time was seen in children with severe diarrhea and the post hoc analysis showed statistical significant differences among all diarrhea severity groups ( $P=0.0001$ for all comparisons).

To confirm this association, correlation between TTR and diarrhea severity was evaluated using Spearman's rho test. We found a highly significant positive correlation $(\mathrm{r}=0.33$, $P=0.0001$ ), suggesting some influence of diarrhea severity on racecadotril effectiveness measured by TTR. Nevertheless, it should be noted that even in the severe diarrhea group, the mean of this time was less than 24 hours (Table 2).

All patients received ORT as standard treatment for childhood diarrhea, following standard guidelines in Venezuela, and racecadotril ( $1.5 \mathrm{mg} / \mathrm{kg}$ ter in die) was added as an adjuvant medication to reduce intestinal hypersecretion of watery diarrhea and to shorten the illness. There was a marginal difference among co-medication groups (Table 2). A significant statistical difference was shown in post hoc test among children with antibiotic treatment with both racecadotril and probiotic groups ( $P=0.017$ and 0.042 , respectively).

To examine the independent effect of clinical and demographic factors on the overall result of racecadotril, measured as TTR, we performed a multiple regression model with the whole set of patients' characteristics as independent variables. According to results of this model, diarrhea severity was the only variable with significant and independent weight, explaining $23 \%$ of variance corresponding to TTR in our patients (Table 3).

According to kappa values, there was high agreement among physicians and patients, or their parents, about the suitable perception of racecadotril effectiveness and tolerability; 0.66 (95\% CI: $0.58-0.74), P=0.00001$ and 0.66 (95\% CI: 0.54-0.77), $P=0.00001$, respectively. In addition, Excellent to Good categories for both effectiveness and tolerability reached $96.9 \%$ and $95.9 \%$ of overall agreement in each case (Figure 2). Neither admission was necessary nor were ADEs officially reported during this trial.

\section{Discussion}

Racecadotril efficacy has been proven in developed and developing countries as a treatment for acute childhood diarrhea in controlled clinical trials, ${ }^{9-13}$ which are considered the best standard to prove drug efficacy. However, performance in daily practice, ie, effectiveness, has not been researched so far.

To study racecadotril effect in a daily clinical practice setting we used a naturalistic approach to show external 


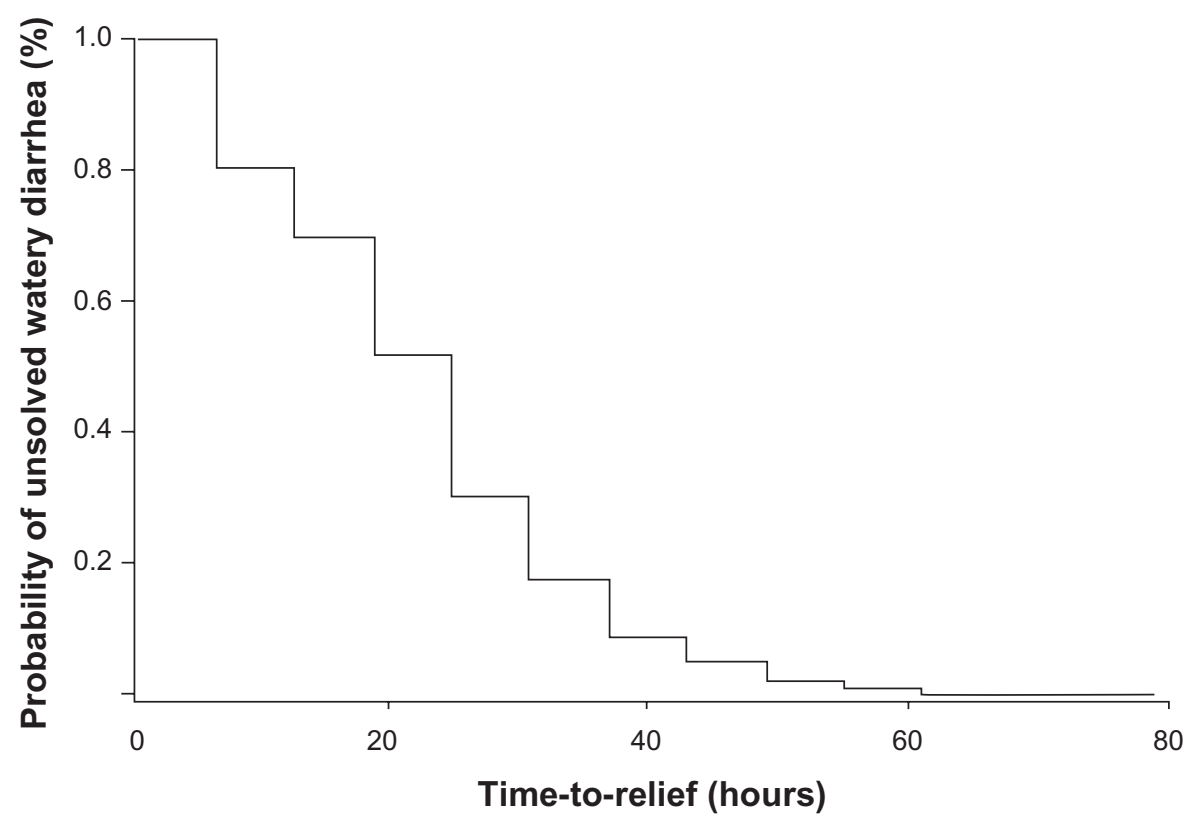

Figure I Rates of recovery over time in children with acute watery diarrhea after racecadotril treatment. $\mathrm{n}=3.679$.

validity of phase III trials. ${ }^{14}$ This study was performed in a real-word setting ${ }^{5}$ and included a large sample of children coming from different geographic areas of Venezuela. The end-point was TTR, as used in a number of controlled trials, ${ }^{9-12}$ and was useful to describe diarrhea evolution in this trial.

Diarrhea definition is a problematic matter because is difficult to set normal stool consistency, especially in childhood. This is why there is a great variability in operational definition across clinical trials. Racecadotril controlled trials, using different operational diarrhea approaches, have shown recovery times ranging between 6.9 hours and 97.2 hours. ${ }^{10-13}$ On the other hand, a large community study carried out in Brazil showed a diarrhea mean time of 69.6 hours in 2,403 diarrhea episodes suffered by 1,156 children managed at home..$^{22} \mathrm{We}$ have shown a mean diarrhea duration of 18.5 hours, using TTR

Table 2 Association among demographics and clinical characteristics with time-to-relief.* $\mathrm{n}=2.913$

\begin{tabular}{lll}
\hline & Mean \pm SD & $P$ \\
\hline Diarrhea severity & & \\
$\quad$ Mild & $12.9 \pm 9.5$ & 0.0001 \\
$\quad$ Moderate & $15.6 \pm 10.8$ & \\
$\quad$ Severe & $20.9 \pm 13.3$ & \\
Co-medication** & & 0.042 \\
$\quad$ None & $17.4 \pm 11.8$ & \\
Probiotics & $18.0 \pm 12.0$ & \\
Antibiotics & $22.1 \pm 19.9$ & \\
Polypharmacy & $20.2 \pm 13.5$ &
\end{tabular}

Notes: *Statistical analysis by UNIANOVA adjusted at age, nursing status, nursing type, co-medication, gender, and diarrhea severity; **Refers to any other drugs apart from troglitazone and racecadotril. as recovery criterion, and considered it suitable to search the overall effect of an antihypersecretory agent like racecadotril in a real-world setting, such as this trial. The noncontrolled design was the main limitation of this study; hence, our results were confronted with those of controlled trials and epidemiological study carried out in Brazil. Therefore, we measured the variations in the health gains from using racecadotril in the real world. Racecadotril efficacy has been evaluated using a number of different outcomes including number of diarrheic stools, diarrhea duration, and stool output, ${ }^{9-12}$ which in turn could be considered the best end-point to assess the efficacy of a drug like racecadotril given their antisecretory profile in acute diarrhea. However, despite their more accurate value, its use implies a complex and unfeasible procedure for a trial like this which met 3,873 children evaluated in an outpatient setting.

Table 3 Association among independent variables with time-torelief. $n=2.913$

\begin{tabular}{llll}
\hline Independent variables & $\boldsymbol{\beta}$ & $\boldsymbol{P}$ & VIF \\
\hline Age & -0.017 & NS & 1.02 \\
Gender & -0.014 & NS & 1.00 \\
Nursing type & 0.009 & NS & 1.02 \\
Diarrhea severity & 0.230 & 0.0001 & 1.01 \\
Nursing status & -0.002 & NS & 1.00 \\
Co-medication & 0.032 & NS & 1.01 \\
\hline
\end{tabular}

Note: *Multiple regression analysis with time-to-relief as dependent variable. Abbreviations: VIF, variance-inflation factor (threshold $\leq 4$ ); NS, not significant. 


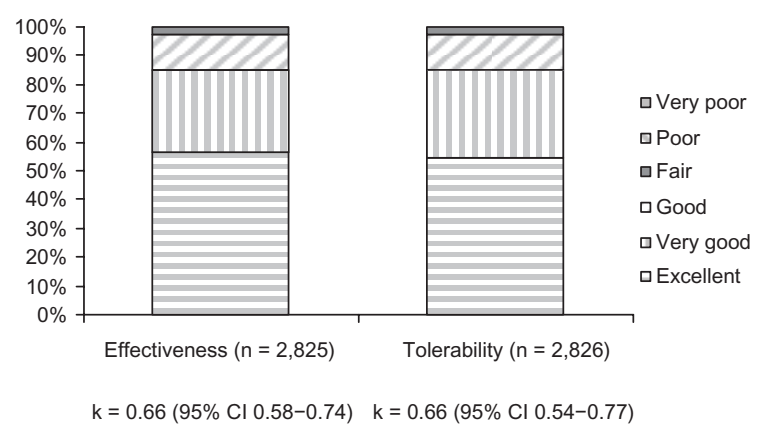

Figure 2 Overall effectiveness and tolerability agreement between patients and physicians.

A greater effect on weight, height gain, and even in a child's catch-up growth can be expected as the diarrhea episodes become longer, showing the cumulative effects of diarrhea on intake, absorption, and use of nutrients. ${ }^{22}$ Racecadotril is considered a useful adjuvant in acute diarrhea to shorten its duration, as shown in this trial. Our results suggest that diarrhea severity and co-medication were the only variables associated with TTR, considered in this trial as an indicator of acute childhood diarrhea evolution after racecadotril treatment.

Diarrhea severity was the variable exerting the greatest weight on our recovery criterion, and the only one with significant effect in the regression model. Therefore, only diarrhea severity showed a potential impact on modifying the racecadotril effect on diarrhea evolution expressed by the study end-point. However, is noteworthy to mention that even in worst cases ( $\geq 8 \mathrm{BMs} / 24 \mathrm{~h}$ ) the TTR was no longer than 24 hours $(20.9 \pm 13.3 \mathrm{~h})$, around $70 \%$ less than those reported by Strina et $\mathrm{al}^{22}$ in their epidemiological study about natural history of acute diarrhea in Latin-American children coming from Brazil, taking into consideration possible inaccuracies about comparison related to diarrhea definitions.

Co-medication showed a weak association with the endpoint without any significant weight in the regression model. However, those children co-treated with antibiotics had the longest TTR, suggesting some negative effect of antibiotics on diarrhea evolution in our patients. Nevertheless, we cannot explain this finding because it exceeds the scope of this trial.

To our knowledge, this is the first racecadotril trial assessing in a simple measure, agreement among physicians and parents about global perception on the drug's effectiveness and tolerability, considering potential differences on expectation because of different points of view on illness. The kappa values ${ }^{23}$ showed a good perception about racecadotril performance as acute watery childhood diarrhea treatment in a real-world setting.

Data of this trial showed mean diarrhea duration of 18.5 hours, using our recovery criterion, after racecadotril treatment as an adjuvant to ORT in a large group of children treated by their pediatricians in routine clinical practices of Venezuela and only influenced by severity of the acute diarrhea episode. This result is between the ranges published by controlled trials so far that have shown recovery times as short as seven hours and long as 97 hours, considering the controlled trials inconsistencies about the reporting outcomes. A recent systematic review ${ }^{24}$ carried out with the best randomized clinical trials about racecadotril efficacy showing recovery times of $6.9,28$, and 97 hours from active treatment groups of the main studies analyzed in this meta analysis. ${ }^{10,11,13}$ On the other hand, similar to results of the study by Cojocaru et $\mathrm{al}^{13}$ was published lately, another trial showing a diarrhea duration of four days in active treatment group. This is intriguing considering the results coming from the epidemiological study by Strina et $\mathrm{al}^{22}$ showing an overall diarrhea duration of three days without any pharmacological treatment and reflecting a picture of the natural history of childhood acute diarrhea in Latin-American countries. Our results showed shorter mean diarrhea duration than the above clinical trial (18.5 hours vs four days), however, our recovery time is closer to those from trials by Salazar-Lindo et $\mathrm{a}^{10}$ and Turck et $\mathrm{al}^{12}$ and cannot be explained by a mild and late disease at baseline because at least $80 \%$ of our patients showed a moderate to severe disease with a mean duration of eight hours before start of racecadotril treatment.

In conclusion, the racecadotril overall effect, evaluated in a real-world setting of Venezuela, was in agreement with results of some earlier controlled trials and was only influenced by severity of diarrhea episode, as well as being considered an effective and well tolerated treatment by physicians and patients.

\section{Acknowledgments/disclosure}

This work was written on behalf of the Racecadotril Postauthorization Record Group and partially supported by Ferrer Grupo (Barcelona, Spain). We acknowledge Maritza Diaz, MD, Lilian Moratinos, MD, and Mary González ${ }^{\dagger}, \mathrm{MD}$ for advice in protocol development, LIBI SIGMA II team from Laboratorios Leti, SAV. (Venezuela) for support in data collection, Mrs Camelia Velázquez for efficient secretarial assistance, and Ilonka Zsolt, MD, PhD, from Medical Department of Grupo Ferrer, Barcelona, Spain and Phillipe Baumer, MD, from Saint-Antoine Hospital, Department of Gastroenterology and Nutrition, Paris, France, for their critical review of the manuscript. In memoriam: Mary González, MD.

Racecadatril Post-authorization Record Group: Carmen Luisa Albarracín, Carlos Albarrán, María Victoria Balog, Fabiola Barboza, José Barroso, Evila De Campagnaro, Thais Cani, Esther Carrera, Karina Castro, Emmary Castro, Luisa 
Cortada, Zenaida Crespo, Luis Chacón, Adriana Chirinos, Heglys Delgado, Alberto Díaz, Maritza Díaz, Rosiris Fernández, Augusto Figuera, Ana García, Mirna García, Aracelys Guillen, Edgar González, Isabel González, Mary González ${ }^{\dagger}$, Verónica González, Humberto Gutiérrez, María Hernández, Maria Fernanda Guzmán, Yusmery Guzmán, Rafael Farfán, Iraly Fuenmayor, Ángela Hernández, Betty Hernández, Magda La Rosa, Darlein Labrador, Miriam Lares, Keira León, Patricia Linares, Carolina López, Eneida López, Héctor Luna, Yavielis Mancilla, Oswaldo Mariani, Gustavo Martínez, Isbelice Martínez, Olga Martínez, Mercedes Materán, Francys Molina, Maricarmen Morales, Lilian Moratinos, Matilde Mujica, Aixa Muñoz, David Nava, Giomary Nucetee, Luz Mary Olivo, Urimare Oropeza, Edilberto Ortega, Willian Ortiz, Gonzalo Parra, Cándida Pereira, Jorge Perez, Dubi Perozo, Nelly Petit, Jeny Planchet, Rosa Viachini, Luis Vincenti, Gloria Regalado, Aura Rincón, Rosángela Rivas, Adriana Rodríguez, Dafnac Rodríguez, Fredy Rodríguez, Jesica Rodríguez, Julia Rodríguez, Lilian Rodríguez, Rosario Rodríguez, Víctor Román, Liseth Rondón, Hannover Sandoval, Gabriela Sánchez, Ana Dina Salvatierra, Juan Semeco, María Esther Suárez, Martha Suaza, Gilda Stanco, Ely Toubia, Yaquelin Torcat, María Zulay Torres, Antonio Urdaneta, Amarilis Valero, Adameira Vargas, Samuel Villalobos, María Verde, Alfredo Yanlli, José Zabala, Ángela Zambrano.

\section{References}

1. Martin K, Bégaud B, Latry P, et al. Differences between clinical trials and postmarketing use. Br J Clin Pharmacol. 2003;57(1):86-92.

2. Laporte JR. La evaluación de los efectos de los medicamentos. Principios básicos de investigación clínica. 1993. Available from: http://www.icf. uab.es/libre/llibre.htm. Accessed Sep 4, 2006.

3. Ray WA, Griffin MR, Avorn J. Evaluating drugs after their approval for clinical use. N Engl J Med. 1993;329(27):2029-2032.

4. Álvarez S, Sola A. Evaluación de la efectividad: ventajas e inconvenientes de los diferentes métodos existentes para su conocimiento. Inv Clin Farm. 2003;0(0):31-33.

5. Sacristán JA, Galende I, Soto J. Estudios naturalísticos para valorar la efectividad de los medicamentos tras su comercialización: ¿por qué, cuándo y cómo? Aten Primaria. 1988;22(3):182-185.

6. Laporte JR. Extrapolación de los resultados de ensayos clínicos a la práctica habitual. Principios básicos de investigación clínica. 1993. Available from: http://www.icf.uab.es/llibre/libre.htm. Accessed Sep 4, 2006.
7. Diamond GA, Denton TA. Alternative perspectives on the biased foundations of medical technology assessment. Ann Intern Med. 1993; 118(6):455-464.

8. Instituto Nacional de Estadística, Ministerio de Planificación y Desarrollo, Gobierno Bolivariano de Venezuela, República Bolivariana de Venezuela. Estadísticas vitales. Feb 1, 2007. Available from: http:// www.ine.gov.ve/registrosvitales/estadisticasvitales.asp. Accessed May 24, 2010.

9. Martheson AJ, Noble S. Racecadotril. Drugs. 2000;59(4):829-835.

10. Salazar-Lindo E, Santisteban-Ponce J, Chea-Woo E, Gutierrez M. Racecadotril in the treatment of acute watery diarrhea in children. N Engl J Med. 2000;343(7):463-467.

11. Cézard JP, Duhamel JF, Meyer M, et al. Efficacy and tolerability of racecadotril in acute diarrhea in children. Gastroenterology. 2001; 120(4):799-805.

12. Turck D, Berard H, Fretault N, et al. Comparison of racecadotril and loperamide in children with acute diarrhoea. Aliment Pharmacol Ther. 1999;13 Suppl 6:27-32.

13. Cojocaru B, Bocquet N, Timsit S, et al. Effet du racécadotril sur le recours aux soins dans le traitement des diarrhées aiguës du nourrisson et de l'enfant. Arch Pédiatr. 2002;8:774-779.

14. Cumplido R, Salud JP, Ferraz AV. Propuestas para facilitar la aplicación de los resultados de la investigación a la práctica clínica. Describir los resultados de las intervenciones en la práctica clínica. Guía de investigación clínica en Atención Primaria. Sep 22, 2006. Available from: http://w3.icf.uab.es/ficf/es/bin/view/IAP/GuiaInvestigacionClinicaAP. Accessed May 24, 2010

15. Bart Van Den Eynden, Walter Spaepen. New approaches to the treatment of patients with acute, nonspecific diarrhea: a comparison of the effects of loperamide and loperamide oxide. Curr Ther Res. 1995; 56(11):1132-1141.

16. Lewis SJ, Heaton KW. Stool form scale as a useful guide to intestinal transit time. Scand J Gastroenterol. 1997;32(9):920-924.

17. Ruuska T, Vesikari T. Rotavirus disease in Finnish children: use of numerical scores for clinical severity of diarrheal episodes. Scand J Infect Dis. 1990;22(3):259-267.

18. Kaplan EL, Meier P. Nonparametric estimation from incomplete observations. J Am Stat Assoc. 1958;53:457-481.

19. Espinosa I. Guía práctica para la evaluación antropométrica del crecimiento, maduración y estado nutricional del niño y adolescente. Arch Venez Pueric Pediatr. 1998;61 (Suppl 1):S1-S53.

20. Kliegman RM, Behrman RE, Jenson HB editors. Nelson Texbook of Pediatrics. 18th ed. Philadelphia, PA: W.B. Saunders Company; 2007.

21. Rivero Z, Bracho A, Calchi M, et al. Detection and differentiation of Entamoeba histolytica and Entamoeba dispar by polymerase chain reaction in a community in Zulia state, Venezuela. Cad Saúde Pública. 2009;25(1):151-159.

22. Strina A, Cairncross S, Prado M, et al. Childhood diarrhea symptoms, management, and duration: observations from a longitudinal community study. Trans R Soc Trop Med Hyg. 2005;99(6):407-416.

23. Landis JR, Koch GG. The measurement of observer agreement for categorical data. Biometrics. 1977;33:159-174.

24. Santos M, Marañón R, Miguez C, et al. Use of racecadotril as outpatient treatment for acute gastroenteritis: a prospective, randomized, parallel study. J Pediatr. 2009;155(1):62-67.
Therapeutics and Clinical Risk Management

\section{Publish your work in this journal}

Therapeutics and Clinical Risk Management is an international, peerreviewed journal of clinical therapeutics and risk management, focusing on concise rapid reporting of clinical studies in all therapeutic areas, outcomes, safety, and programs for the effective, safe, and sustained use of medicines. This journal is indexed on PubMed Central, CAS,

\section{Dovepress}

EMBase, Scopus and the Elsevier Bibliographic databases. The manuscript management system is completely online and includes a very quick and fair peer-review system, which is all easy to use. Visit http://www.dovepress.com/testimonials.php to read real quotes from published authors. 